\title{
Deposition of carotenoids in egg yolk by short-term supplement of coloured carrot (Daucus carota) varieties as forage material for egg-laying hens
}

\author{
Marianne Hammershøj, ${ }^{a *}$ Ulla Kidmose ${ }^{b}$ and Sanna Steenfeldt ${ }^{c}$
}

\begin{abstract}
BACKGROUND: Supplying egg-laying hens with different forage materials may influence egg production and quality. The aim of this study was to examine the short-term effects of standard feed plus $70 \mathrm{~g} \mathrm{day}^{-1}$ per hen of three coloured carrot varieties (orange, yellow and purple) as forage material in comparison with a standard feed control on egg production, egg yolk colour and deposition of carotenoids in the yolk.

RESULTS: Carrot supplementation reduced feed intakes significantly, but not on a dry matter basis. Orange carrot treatment significantly reduced egg mass production, whereas yellow and purple carrot treatments did not differ from the control. Egg and yolk weights of all carrot-supplemented treatments were significantly lower than those of the control, but yolk percentages were similar. Yolk redness increased significantly in the order control < yellow < orange < purple. A similar trend was seen for yolk yellowness, but yellow and orange carrots reached the same level. Yolk colour and carotenoid contents correlated positively and significantly. In particular, purple carrot treatment increased the yolk content of lutein ( $>1.5$-fold) and $\beta$-carotene (>100-fold) compared with the control.
\end{abstract}

CONCLUSION: Supplementing the feed of egg-laying hens with coloured carrots efficiently increased yolk colour parameters and carotenoid contents, which gives opportunities for improved nutritional value of eggs from forage material-supplemented hens.

(c) 2010 Society of Chemical Industry

Keywords: egg; carotenoids; lutein; yolk colour; carrot; forage material

\section{INTRODUCTION}

Many foods contain carotenoids, which act as pigmenters in e.g. carrots, tomatoes, maize, paprika and egg yolk. Carotenoids have been used as pigments for many years in poultry diets in order to obtain a desired colour of egg yolk or broiler skin. ${ }^{1}$ The carotenoids $\alpha$-and $\beta$-carotene and $\beta$-cryptoxanthin are precursors of vitamin $A$ and have antioxidant properties. ${ }^{2}$ Carotenoids are health promoting by disease prevention in $\operatorname{man}^{2-4}$ as well as stimulating the antibody response in the hen. ${ }^{5}$ In particular, lutein and zeaxanthin are found important in human protection against age-related macular degeneration (ARMD). ${ }^{6}$ Lutein and zeaxanthin are xanthophylls without provitamin A activity, but their dietary intake is generally low $\left(\sim 0.6-3 \mathrm{mg} \mathrm{day}^{-1}\right){ }^{3,7,8} \mathrm{Ap}$ parently, daily intakes of 4-20 mg are required in order to achieve effects in human visual functions. ${ }^{6}$ Lutein is a lemon/yellow carotenoid found in e.g. marigold and alfalfa, while zeaxanthin is a yellow/orange carotenoid quite specific to maize. ${ }^{9}$ Egg yolk is also an important lutein source owing to the relatively high proportion and high bioavailability of its lutein. ${ }^{10,11}$ The lutein content of egg yolk depends on e.g. feed and production system. For example, organic eggs were found to contain approximately two to three times more lutein than conventional eggs in Denmark, ${ }^{8}$ whereas a study in the UK showed the content of lutein in conventional eggs to be two to four times higher than that in organic eggs. ${ }^{12}$ This difference may originate from the type of cereal used in the diet, as e.g. diets rich in wheat will present low levels of lutein.

Carrots are a source of mainly carotenes and to a minor extent xanthophylls, but the content varies widely. Orange-coloured carrots contain mainly $\alpha$ - and $\beta$-carotene and small amounts of lutein, whereas carrot varieties of e.g. purple, red or yellow colour have different carotenoid compositions..$^{13-15}$ Speciality carrots of different colours have attracted increased consumer interest and acceptance. ${ }^{13}$ In carrot production for the food market, low-quality

* Correspondence to: Marianne Hammershøj, Department of Food Science, Faculty of Agricultural Sciences, Aarhus University, DK-8830 Tjele, Denmark. E-mail:marianne.hammershoj@agrsci.dk

a Department of Food Science, Faculty of Agricultural Sciences, Aarhus University, DK-8830 Tjele, Denmark

b Department of Food Science, Faculty of Agricultural Sciences, Aarhus University, DK-5792 Arslev, Denmark

c Department of Animal Health and Bioscience, Faculty of Agricultural Sciences, Aarhus University, DK-8830 Tjele, Denmark 
carrots (up to $22 \%$ by weight) are rejected owing to e.g. root size, deformation, breakage, disease or infection. ${ }^{16}$ As the production of other coloured varieties increases, the availability of rejected carrots thereof will also increase. They represent low economic value and are usually used as animal feed without regarding them as a carotenoid source. One way to exploit the health-promoting components from rejected carrots and potentially increase their value could be their use in organic egg production, where access to forage material is mandatory. Carrots have become common as forage material in organic egg production in Denmark. However, only a few scientific studies have dealt with the effects of dietary carrots on egg production and egg quality. ${ }^{17-19}$

Usually, dried synthetic or natural pigments are used in poultry diets, as they are well-defined pigmenters, easy to handle, and allow easy targeting and high reproducibility of any desired yolk colour. ${ }^{1}$ Studies have shown that purified lutein and lutein from dried dietary sources of marigold, alfalfa and paprika are readily absorbed and deposited in the egg, $, 912,20$ thereby supplying the egg with high lutein concentrations of $31.1,{ }^{20} 106.3^{12}$ and $113^{7}{\mu g^{-1}}^{-1}$ yolk, approximately $11-18$ times higher than in non-lutein-supplemented eggs. The carotenoid deposition and composition in egg yolk derived from hens fed carrots are not reported in the literature. Only the effect of $8 \%(\mathrm{w} / \mathrm{w})$ carrots in layer diets on egg production ${ }^{18}$ and the effect of $8 \%(\mathrm{w} / \mathrm{w})$ dried carrot meal or mixed maize silage and carrots as forage material on egg yolk colour ${ }^{17,19}$ have been reported. All these experiments were performed with orange carrot varieties.

The objective of the present study was to examine the short-term effect of using different coloured carrot varieties as forage material for hens on egg performance, egg yolk colour and deposition of carotenoids in the yolk.

\section{MATERIALS AND METHODS} Hens, housing and feed

Four weeks before the experimental period, 112 Hy-Line ${ }^{\circledR}$ Variety Brown pullets at the age of 18 weeks were placed in a deeplitter pen to acclimatise to the environment. The pullets were not beak-trimmed. Throughout the period before and during the experiment the birds were fed a commercial organic standard feed (The DLG Feed Company, Copenhagen, Denmark). The composition, calculated and analysed contents were supplied by the feed company (Table 1). The day length during the experiment was $16 \mathrm{~h}$ light $/ 8 \mathrm{~h}$ dark.

Five days prior to the experiment the 112 hens were randomly distributed into 16 deep-litter pens of four dietary treatments in four replicates, so each pen contained seven hens at a density of 1.6 hens $\mathrm{m}^{-2}$. Adjacent pens were divided by walls of wooden plates and wire mesh. Each pen was equipped with five nipple drinkers, one round feed trough, and wood shavings as litter material. Furthermore, each pen where carrots were supplied had a wooden box for the purpose.

\section{Experimental design}

The experimental period of 28 days started at the hen age of 22 weeks and contained the following four dietary treatments: C) (control) standard feed ad libitum without supply of forage material; P) standard feed ad libitum plus supply of $70 \mathrm{~g}^{\text {day }}{ }^{-1}$ per hen of carrot variety Purple Haze (purple root with orange core); $Y$ ) standard feed ad libitum plus supply of $70 \mathrm{~g} \mathrm{day}^{-1}$ per hen of carrot variety Rainbow (yellow root); O) standard feed ad libitum plus
Table 1. Organic standard feed composition, calculated and analysed nutrients $\left(\mathrm{g} \mathrm{kg}^{-1}\right)$

\begin{tabular}{|c|c|}
\hline Ingredient & Amount \\
\hline Wheat & 425.0 \\
\hline Oats & 150.0 \\
\hline Peas & 150.0 \\
\hline $\mathrm{CaCO}_{3}$ (limestone) & 64.6 \\
\hline Sunflower meal (hulled) & 60.0 \\
\hline Fish meal & 45.0 \\
\hline Corn gluten (60\%) & 35.0 \\
\hline Oyster shells & 20.0 \\
\hline Green meal & 20.0 \\
\hline Rapeseed oil & 12.0 \\
\hline $\mathrm{CaHPO}_{4}$ & 10.5 \\
\hline Vitamin/mineral premix ${ }^{a}$ & 4.0 \\
\hline $\mathrm{NaCl}$ & 1.3 \\
\hline Sodium bicarbonate & 1.0 \\
\hline Avizyme $^{\circledR} 1300^{\mathrm{b}}$ & 0.7 \\
\hline Betaine anhydrate & 0.5 \\
\hline Choline chloride & 0.4 \\
\hline \multicolumn{2}{|l|}{ Calculated values } \\
\hline Metabolisable energy (MJ kg ${ }^{-1}$ ) & 10.8 \\
\hline Crude protein & 163 \\
\hline Crude fat & 46 \\
\hline Lysine & 7.5 \\
\hline Methionine & 3.1 \\
\hline Methionine + cystine & 6.1 \\
\hline \multicolumn{2}{|l|}{ Analysed values } \\
\hline Metabolisable energy (MJ kg ${ }^{-1}$ ) & 11.0 \\
\hline Crude protein & 149 \\
\hline Crude fat & 51 \\
\hline Starch & 398 \\
\hline Sugar & 26 \\
\hline Calcium & 35.8 \\
\hline Phosphorus (available) & 6.5 \\
\hline
\end{tabular}

supply of $70 \mathrm{~g} \mathrm{day}^{-1}$ per hen of carrot variety Bolero (orange root). Referring to previous studies, ${ }^{19,21}$ laying hens are able to consume about $120 \mathrm{~g} \mathrm{day}^{-1}$ of forage material. However, as the high sugar and water content in carrots may result in wetter excreta, ${ }^{21}$ a carrot amount of $70 \mathrm{~g} \mathrm{day}^{-1}$ per hen was chosen to minimise wet litter.

The three carrot varieties used were grown in the same fields in Funen, Denmark, harvested 2 days prior to the experimental period and stored within $24 \mathrm{~h}$ in wooden boxes at $4{ }^{\circ} \mathrm{C}$. Continuously throughout the experimental period, appropriate portions of carrots were taken from cold storage 1 week before feeding and kept at the stables. Samples of about $250 \mathrm{~g}$ of carrot per cultivar and of the organic standard feed were collected and stored at $-20^{\circ} \mathrm{C}$ until carotenoid analysis. For the first 3 days of the experimental period the carrots were chopped into $5-10 \mathrm{~mm}$ pieces; thereafter they were fed as unprocessed whole roots. The carrots were weighed before being supplied each morning after eventual leftovers from the previous day had been removed and weighed.

Feed consumption was registered weekly per pen. Carrot consumption, egg production and bird mortality (two out of 
112 hens) were registered daily. Data recording began 3 days prior to the experimental period.

\section{Egg collection and yolk colour analysis}

During the experimental period of 28 days, eggs were collected for analysis nine times, four eggs from each of the 16 pens, i.e. a total of 576 eggs. Individual eggs were weighed and broken and the yolk was separated from the albumen. The yolk colour was analysed by a Minolta Chroma Meter CR-300 (Minolta Co. Ltd., Osaka, Japan) using the CIE (Commission Internationale d'Eclairage) Lab scale with standardised daylight (D65). The $L^{*}, a^{*}$ and $b^{*}$ values reflect lightness $(0=$ black, $100=$ white $)$, redness $(-100=$ green, $100=$ red) and yellowness $(-100=$ blue, $100=$ yellow) respectively. The instrument was calibrated daily against a white standard plate. Furthermore, based on the specific readings and calibrations of the Minolta instrument and corresponding Roche yolk colour (RYC) fan readings of yolk colour, a correlation equation was found between these. As the $a^{*}$ value turned out to have the highest correlation coefficient $\left(r^{2}=0.9899\right)$, the following equation was used to transform instrument readings into RYC values: $Y$ (RYC) $=0.62$ ( $a^{*}$ value $)+8.00$. The yolk was rolled on a paper tissue to remove albumen remains, and the chalazas were cut off before weighing the yolk. The yolk as a proportion (\%) of the whole egg was calculated. Individual yolk samples without membranes were stored at $-20^{\circ} \mathrm{C}$ until carotenoid analysis.

\section{Preparation of feed, carrot and egg yolk samples for analysis of carotenoids}

Samples of $1 \mathrm{~g}$ after homogenisation were transferred to $100 \mathrm{~mL}$ brown flasks. A volume of $24 \mathrm{~mL}$ of $1000 \mathrm{~mL} \mathrm{~L}^{-1}$ ethanol of high-performance liquid chromatography (HPLC) grade (Rathburn Chemicals Ltd, Walkerburn, UK) was added and the flask contents were homogenised at $15000 \mathrm{rpm}$ for about $4 \mathrm{~min}$ by an Ultra Turrax (IKA ${ }^{\circledR}$-Labortechnik, Janke \& Kunkel GmbH \& Co., Staufen, Germany). Then $9 \mathrm{~mL}$ of $1000 \mathrm{~mL} \mathrm{~L}^{-1}$ methanol with $25 \mathrm{~mL} \mathrm{~L}^{-1}$ butylhydroxytoluene (BHT) and $5 \mathrm{~mL}$ of saturated $\mathrm{KOH}$ were added. The flasks were filled with argon and incubated in a shaking water bath at $70^{\circ} \mathrm{C}$ for $2 \mathrm{~h}$. Subsequently, samples were cooled at $4{ }^{\circ} \mathrm{C}$ for $30 \mathrm{~min}$ and filtered through a Whatman No. 40 filter paper (Frisenette ApS, Ebeltoft, Denmark) into clean $100 \mathrm{~mL}$ brown flasks.

Egg yolk samples of $0.2 \mathrm{~g}$ were weighed into $10 \mathrm{~mL}$ pyrex glass vials and deionised water was added up to $1 \mathrm{~mL}$. Then $2 \mathrm{~mL}$ of $1000 \mathrm{~mL} \mathrm{~L}^{-1}$ ethanol with $10 \mathrm{~mL} \mathrm{~L}^{-1} \mathrm{BHT}$ was added and mixed for $10 \mathrm{~s}$ before adding $0.5 \mathrm{~mL}$ of saturated $\mathrm{KOH}$ and mixing for $10 \mathrm{~s}$. The vials were filled with argon and incubated in a heating cabinet at $70^{\circ} \mathrm{C}$ for $90 \mathrm{~min}$, mixing four times during the incubation. Afterwards the vials were cooled on ice to room temperature.

\section{Extraction and HPLC analysis of carotenoids}

From the feed, carrot and egg yolk samples, $4 \mathrm{~mL}$ aliquots were transferred to $10 \mathrm{~mL}$ pyrex glass vials. To each vial with either feed, carrot or egg yolk sample, $1 \mathrm{~mL}$ of deionised water and $3 \mathrm{~mL}$ of heptane/tetrahydrofuran $(90: 10 \mathrm{v} / \mathrm{v})$ were added. The vials were shaken vigorously for $1 \mathrm{~min}$ and centrifuged at $1700 \times \mathrm{g}$ for $3 \mathrm{~min}$. The supernatants were transferred to new vials and the extraction procedure was repeated three more times. The extracted supernatants were evaporated on a vacuum centrifuge at $35^{\circ} \mathrm{C}$ for a total time of $75 \mathrm{~min}$ with heating during $60 \mathrm{~min}$ and full vacuum. The resulting residue fractions were redissolved in $1 \mathrm{~mL}$ of EMT (ethanol/methanol/tetrahydrofuran, $75: 20: 5 \mathrm{v} / \mathrm{v} / \mathrm{v}$ ), mixed, filtered through a $0.45 \mu \mathrm{m}$ poly(vinyl difluoride) (PVDF) membrane into HPLC vials and subjected to HPLC analysis.

An HP1100 HPLC system (Hewlett-Packard A/S, Allerod, Denmark) with a diode array detector (DAD) at $450 \mathrm{~nm}$ was used for analysis of carotenoids. A column (YMC Europe $\mathrm{GmbH}$, Dinslaken, Germany) with $5 \mu \mathrm{m} \mathrm{C30}$ reverse phase material of inner dimensions $250 \mathrm{~mm} \times 4.6 \mathrm{~mm}$ was used for separation. A precolumn of inner dimensions $10 \mathrm{~mm} \times 4 \mathrm{~mm}$ was included before the column and held at $25^{\circ} \mathrm{C}$. Isocratic separation was performed with EMT as mobile phase at a flow rate of $1 \mathrm{~mL} \mathrm{~min}^{-1}$. Sample volumes injected were $10 \mu \mathrm{L}$ for feed and carrots and $100 \mu \mathrm{L}$ for egg yolks. All analyses were done in triplicate.

\section{Carotenoid standard solutions for HPLC analysis and quantification of carotenoids}

Commercial standards of relevant carotenoids were used for quantification by dissolving them in EMT to the following concentrations $\left(\mu \mathrm{g} \mathrm{L}^{-1}\right.$ ): lutein 68.300 , zeaxanthin 53.000 , canthaxanthin 44.950, $\beta$-cryptoxanthin 23.475 , $\alpha$-carotene 19.725 and $\beta$-carotene 2050.67.

Zeaxanthin was purchased from Bie \& Berntsen A/S (Herlev, Denmark), lutein and $\beta$-carotene from Sigma-Aldrich Denmark $\mathrm{A} / \mathrm{S}$ (Brøndby, Denmark) and the remaining carotenoids from $\mathrm{DHI}$ Water \& Environment (Hørsholm, Denmark).

The standards were diluted appropriately to prepare standard curves and were subjected to HPLC/DAD analysis as described above. Standard curves of each carotenoid were produced by plotting the relative peak areas at $450 \mathrm{~nm}$ against the carotenoid concentrations. Identification was done by spiking of authentic standards and comparing the spectral data obtained by DAD with reported values. ${ }^{22}$ The contents of individual carotenoids in feed, carrots and egg yolks were quantified on the basis of the corresponding retention times and standard curves. A total carotenoid content was calculated based on the peak area sum of lutein, zeaxanthin, $\alpha$-carotene, $\beta$-carotene, isomer forms of $\beta$-carotene and peaks of unknown identity.

\section{Dry matter content}

The dry matter (DM) content $\left(\mathrm{g} \mathrm{kg}^{-1}\right)$ of feed and carrot samples was determined by heating about $2 \mathrm{~g}$ of homogenised material to $198^{\circ} \mathrm{C}$ until equilibration in an HR73 halogen moisture analyser (Mettler Toledo, Schwerzenbach, Switzerland).

\section{Statistical analysis}

All data were subjected to statistical analysis by the generalised linear model (GLM) procedure of SAS Version 9.2 (SAS Institute Inc., Cary, NC, USA). For each treatment and each egg collection, data were tested for variance homogeneity by the Bartlett test, and outlier values were excluded. The normality of the data distribution was checked by a probit analysis and resulted in the following data transformation: $\log _{10}$ of egg weight and squares of yolk colour $L^{*}$, laying $\%$ and egg mass.

The model of analysis was

$$
Y_{i j l}=a_{i}+b_{j}+c_{i j}+e_{i j l}
$$

where $a$ is the main effect of treatment $i(C, \mathrm{O}, \mathrm{Y}, \mathrm{P}), b$ is the main effect of day $j(1,4,7,11,14,18,21,25,28), c$ is the interaction between treatment and day and $e$ is replicate $I(1, \ldots, 16)$ for egg analyses. For feed intake, $j=7,14,21,28$ and $I=1, \ldots, 4$. If interactions between class variables were non-significant, $c_{i j}$ was 
Table 2. Contents (mean \pm standard deviation) of carotenoids ( $\mathrm{mg} \mathrm{kg}^{-1}$ fresh weight) and dry matter $\left(\mathrm{g} \mathrm{kg}^{-1}\right)$ in three coloured carrot varieties used as forage material and in organic standard feed $(n=3)$

\begin{tabular}{|lcccc|}
$\begin{array}{l}\text { Variety } \\
\text { Colour }\end{array}$ & $\begin{array}{c}\text { Bolero } \\
\text { Orange }\end{array}$ & $\begin{array}{c}\text { Rainbow } \\
\text { Yellow }\end{array}$ & $\begin{array}{c}\text { Purple Haze } \\
\text { Purple }\end{array}$ & $\begin{array}{c}\text { Standard } \\
\text { feed - }\end{array}$ \\
\hline Lutein & $1.7 \pm 0.1$ & $1.9 \pm 0.1$ & $6.5 \pm 0.2$ & $2.9 \pm 0.4$ \\
Zeaxanthin & $0.2 \pm 0$ & $0.1 \pm 0.1$ & $0.3 \pm 0$ & $1.0 \pm 0.1$ \\
$\alpha$-Carotene & $34.2 \pm 1.5$ & $5.6 \pm 0.6$ & $71.2 \pm 2.2$ & $0.2 \pm 0$ \\
$\beta$-Carotene & $84.9 \pm 5.2$ & $15.3 \pm 1.6$ & $121.2 \pm 3.6$ & $0.3 \pm 0$ \\
Total carotenoids & $142 . \pm 7.7$ & $27.3 \pm 2.8$ & $227.4 \pm 6.5$ & $5.1 \pm 0.7$ \\
Dry matter & $115 \pm 12$ & $116 \pm 3$ & $147 \pm 2$ & $877 \pm 2$ \\
\hline
\end{tabular}

excluded from the model. Least squares (LS) means were calculated and differences were regarded as significant at minimum $95 \%$ level $(P \leq 0.05)$ and classified by the Ryan-Einot-Gabriel-Welsch multiple range test.

\section{RESULTS}

The content of carotenoids in the standard feed and the three carrot varieties used as forage material is given in Table 2. As an example, the HPLC chromatograms of carotenoids of the standard feed and the purple carrot variety Purple Haze are shown in Fig. 1 together with chromatograms of egg yolk carotenoids of the control and the purple carrot treatment.

The total carotenoid content in the standard feed was relatively low compared with that in the carrots when considering the differences in concentration on a DM basis (Table 2). The DM content of the purple variety was higher than that of the other two carrot varieties. Thus, calculated on a DM basis, this reduces the relative carotenoid content in the purple carrots. However, the standard feed had a low content of total carotenoids on a DM basis owing to the use of wheat and oats, which contain practically no pigments. The content of lutein and zeaxanthin in the standard feed came from the peas, corn gluten and green meal in the feed (Table 1). The results on consumption of feed and carrots, egg production and feed conversion are given in Table 3 for the experimental period. The hens had a preference for the purple carrots, i.e. they adapted faster to eating whole carrots of this variety.

Supplementation with carrots significantly decreased the daily feed intake by $8-11 \mathrm{~g}$ in all supplemented groups; however, on a DM basis, this was not the case. The DM intake of the control was similar to that of all carrot-supplemented treatments. Only the yellow and purple carrot-supplemented treatments differed in DM intake as a result of the higher DM content, mass intake and feed intake for the purple versus the yellow carrot treatment.

The observed decrease in feed intake resulted in a significantly lower egg weight of hens receiving forage material (Table 3), but the egg-laying rate and consequently the egg mass produced were only significantly reduced for hens receiving orange (Bolero) carrots. The orange carrot treatment gave the significantly lowest egg-laying rate, egg weight and egg mass production, resulting in a significantly higher feed conversion rate (FCR) on a DM basis than the other treatments, which all had comparable low FCRs.

From the registered consumption and the analysed contents of individual carotenoids of the feed and carrots, the daily intake of carotenoids was calculated (Table 3). The daily intake of lutein from the feed was significantly highest in the control group, with a mean value of $0.33 \mathrm{mg}$ per hen $(P<0.001)$, whereas in the carrot-supplemented groups the lutein intake originating from the feed part was about $0.30 \mathrm{mg}$ per hen. This is caused by a general decrease in feed intake, as lutein and zeaxanthin are at higher levels in the standard feed than in the carrots. The intake of carotenoids for the four treatments reached steady state levels after approximately $7-14$ days (Fig. 2).
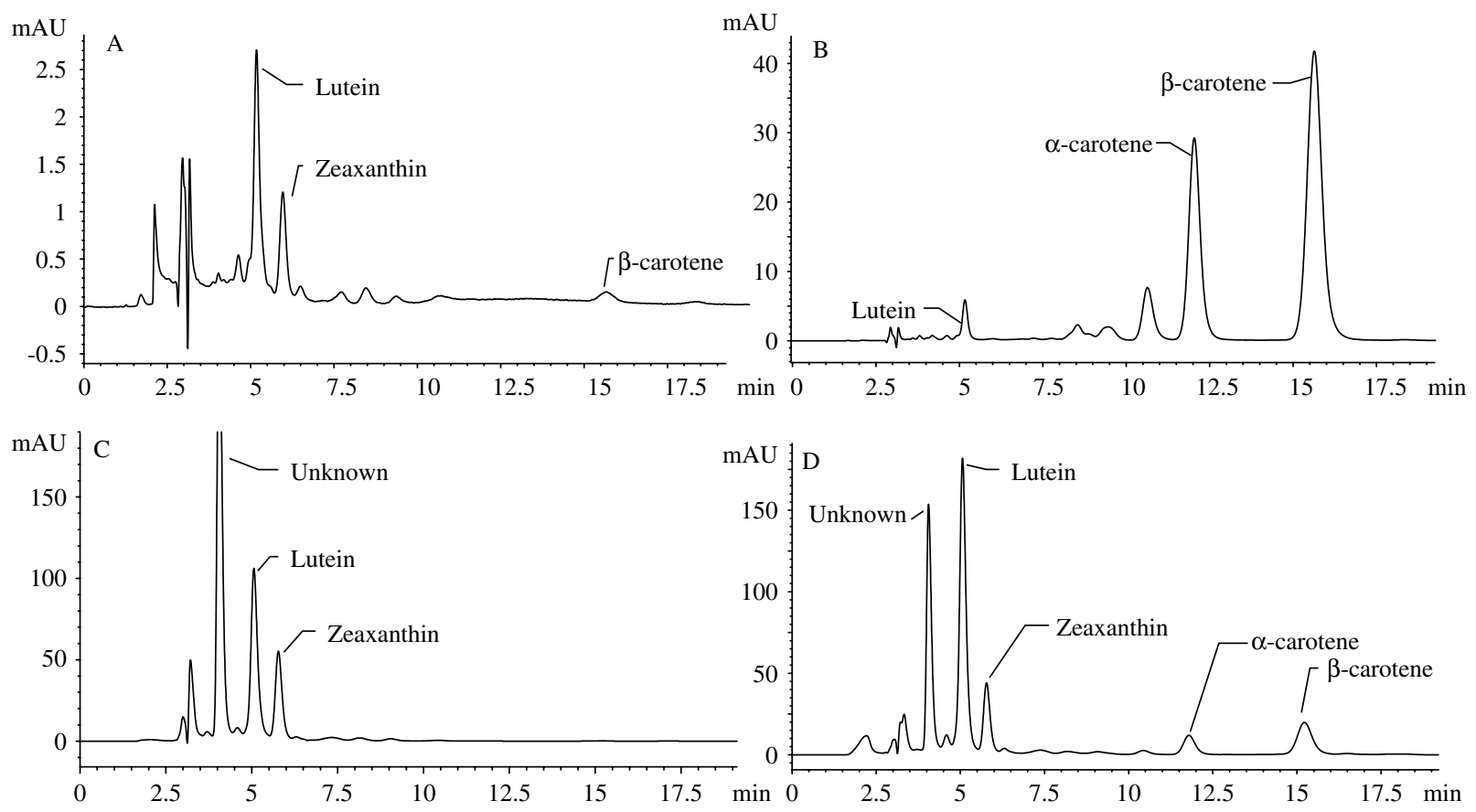

Figure 1. Representative HPLC chromatograms of carotenoids in (A) standard feed, (B) purple carrot variety, (C) egg yolk of control treatment and (D) egg yolk of treatment with purple carrots. Note the different $Y$-axis scales. 


\begin{tabular}{|c|c|c|c|c|c|c|}
\hline Treatment Carrot variety & Control - & $\begin{array}{l}\text { Orange } \\
\text { Bolero }\end{array}$ & $\begin{array}{c}\text { Yellow } \\
\text { Rainbow }\end{array}$ & $\begin{array}{c}\text { Purple } \\
\text { Purple Haze }\end{array}$ & SEM & $F$ test \\
\hline Standard feed intake (g day ${ }^{-1}$ per hen) & $112 \mathrm{a}$ & $104 b$ & $101 b$ & $104 b$ & 1.4 & $P<0.001$ \\
\hline Carrot intake (g day ${ }^{-1}$ per hen) & - & 62 & 63 & 65 & 1.2 & NS \\
\hline Total DM intake (g day ${ }^{-1}$ per hen) & $98.3 a b$ & $98.2 \mathrm{ab}$ & $95.7 b$ & $100.3 a$ & 1.2 & $P<0.05$ \\
\hline Lutein intake (mg day ${ }^{-1}$ per hen) & $0.33 c$ & $0.41 \mathrm{~b}$ & $0.42 b$ & $0.73 a$ & 0.01 & $P<0.001$ \\
\hline Zeaxanthin intake (mg day ${ }^{-1}$ per hen) & $0.11 b$ & $0.12 \mathrm{a}$ & $0.10 c$ & $0.12 \mathrm{a}$ & 0.01 & $P<0.001$ \\
\hline$\alpha$-Carotene intake (mg day ${ }^{-1}$ per hen) & $0.02 d$ & $2.15 b$ & $0.37 c$ & $4.63 a$ & 0.07 & $P<0.001$ \\
\hline$\beta$-Carotene intake (mg day ${ }^{-1}$ per hen) & $0.04 d$ & $5.32 \mathrm{~b}$ & $1.00 \mathrm{c}$ & $7.88 \mathrm{a}$ & 0.13 & $P<0.001$ \\
\hline Total carotenoid intake (mg day ${ }^{-1}$ per hen) & $0.57 d$ & $9.42 b$ & $2.24 \mathrm{c}$ & $15.25 \mathrm{a}$ & 0.23 & $P<0.001$ \\
\hline Egg-laying rate (\%) & $87.6 \mathrm{ab}$ & $83.2 b$ & $90.4 a$ & $92.9 a$ & 0.1 & $P<0.01$ \\
\hline Egg weight (g) & $60.2 a$ & $58.5 b$ & $59.0 \mathrm{~b}$ & $58.8 \mathrm{~b}$ & 0.3 & $P<0.01$ \\
\hline Egg mass (g day ${ }^{-1}$ per hen) & $52.8 \mathrm{a}$ & $48.8 \mathrm{~b}$ & $53.4 a$ & $54.7 a$ & 1.0 & $P<0.001$ \\
\hline Standard feed FCR ( $\mathrm{g} \mathrm{g}^{-1}$ egg) & $2.15 \mathrm{a}$ & $2.19 a$ & $1.92 b$ & $1.92 b$ & 0.05 & $P<0.001$ \\
\hline Total (feed + carrot) FCR (g DM g ${ }^{-1}$ egg) & $1.89 b$ & $2.07 a$ & $1.82 \mathrm{~b}$ & $1.85 \mathrm{~b}$ & 0.04 & $P<0.001$ \\
\hline
\end{tabular}

Values in a row with different letters differ significantly at the level of the $F$ test; NS, not significant $(P>0.05)$.

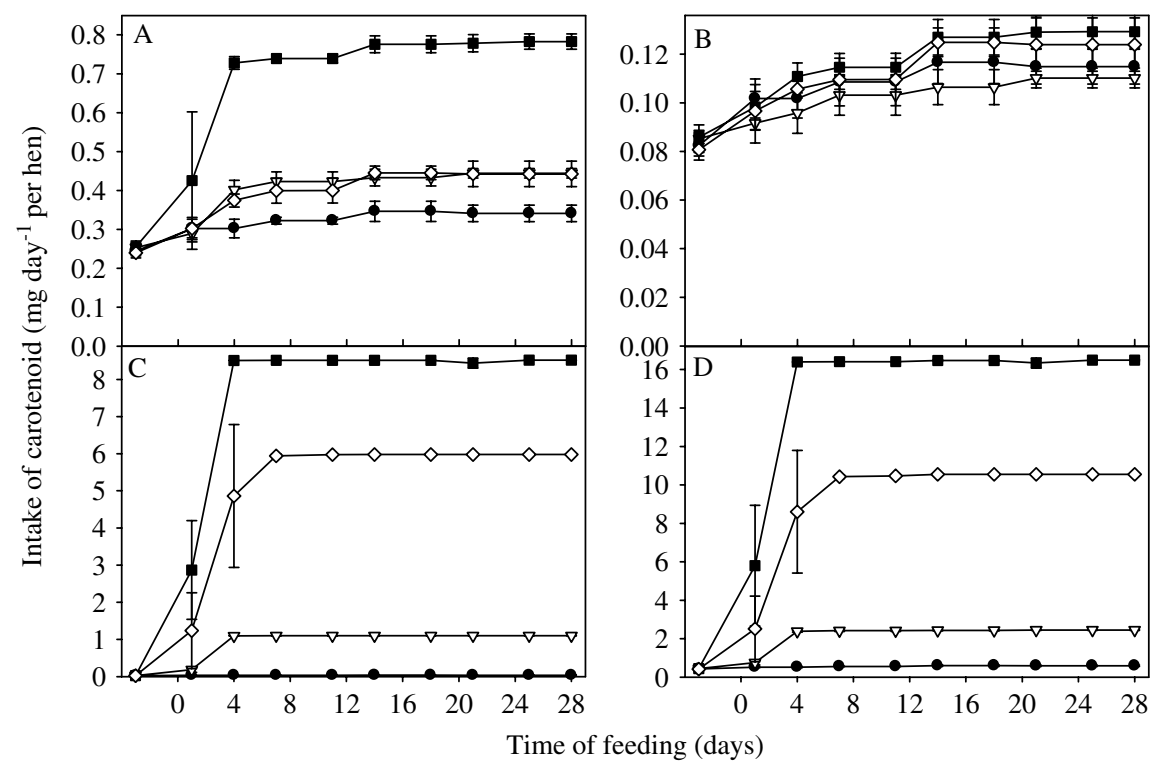

Figure 2. Means \pm SE of daily intake of carotenoids from feed and carrots in four treatments as a function of feeding time of orange carrot Bolero $(\diamond)$, yellow carrot Rainbow $(\nabla)$, purple carrot Purple Haze $(\square)$ and control feed $(\bullet)(n=4)$ : A, lutein; B, zeaxanthin; C, $\beta$-carotene; D, total carotenoids. Note different $Y$-axis scales.

Egg yolk colour, yolk weight and daily yolk mass output were significantly affected by treatment (Table 4). Only yolk percentage was unaffected by treatment, but all parameters were significantly (from $P<0.05$ to $P<0.001$ ) affected by time during the experiment. Significant interactions between treatment and time were found only for yolk colour $a^{*}(P<0.001)$ and $b^{*}(P<0.01)$ (Figs 3 and 4). The control treatment showed an insignificant change over time in yolk colour $a^{*}$ (redness) compared with the three carrot treatments. Supplementation with the purple carrot variety resulted in a significant $(P<0.001)$ effect on yolk colour $a^{*}$ after only 4 days of feeding and showed the highest level with time. Within the first 7 days the orange and yellow carrot varieties showed similar increases in yolk colour $a^{*}$. Hence the orange variety resulted in higher yolk $a^{*}$ values. However, at day 28 the $a^{*}$ values of yolks from orange and yellow carrot treatments were at the same level (Fig. 3). The curves in Fig. 3 indicate pigment accumulation during the first 14 days, after which yolk colour $a^{*}$ reached a relatively steady state.

In Fig. 4, yolk colour $b^{*}$ (yellowness) shows a significant $(P<0.01)$ increasing effect of purple carrot treatment after 7 days and of orange and yellow carrot treatments after 11 days. For yolk colour $b^{*}$ too the purple carrot treatment reached the overall significantly highest level (Table 4).

The deposition efficiency (DE) of carotenoids from feed to egg yolk was calculated essentially as described by Karadas et al., ${ }^{20}$ i.e. DE $(\%)=\left\{\right.$ [yolk carotenoid concentration $\left(\mu \mathrm{g} \mathrm{g}^{-1}\right) \times$ yolk mass production $\left(\mathrm{g} \mathrm{day}^{-1}\right.$ per hen)]/[feed carotenoid concentration $\left(\mu \mathrm{g} \mathrm{g}^{-1}\right) \times$ feed intake $\left(\mathrm{g} \mathrm{day}^{-1}\right.$ per hen $\left.\left.)\right]\right\} \times 100$. Both the contents of carotenoids in egg yolk and the DE values are calculated for the period 1-3 weeks after the introduction of carrots in order to have reached a steady carotenoid intake together with an equilibrium in carotenoid deposition (Table 5). All yolk carotenoids changed 
Table 4. LS means of analysed egg yolk colour $L^{*}, a^{*}$ and $b^{*}$ and yolk parameters and calculated Roche yolk colour (RYC) value for hens at age $22-25$ weeks as a function of carrot supplementation

\begin{tabular}{|c|c|c|c|c|c|c|}
\hline Treatment Carrot variety & Control - & Orange Bolero & Yellow Rainbow & Purple Purple Haze & SEM & $F$ test \\
\hline \multicolumn{7}{|l|}{ Yolk colour } \\
\hline$L^{*}$ & $65.4 a$ & $65.1 \mathrm{ab}$ & $65.3 a$ & $64.6 \mathrm{~b}$ & 0.2 & $P<0.05$ \\
\hline$a^{*}$ & $-4.7 d$ & $-3.6 b$ & $-4.1 c$ & $-3.0 \mathrm{a}$ & 0.1 & $P<0.001$ \\
\hline$b^{*}$ & $48.6 \mathrm{c}$ & $51.3 b$ & $51.2 b$ & $53.1 \mathrm{a}$ & 0.3 & $P<0.001$ \\
\hline RYC value & $4.0 c$ & $4.6 \mathrm{~b}$ & $4.5 b$ & $5.5 b$ & 0.1 & $P<0.001$ \\
\hline Yolk weight (g) & $11.9 \mathrm{a}$ & $11.6 b$ & $11.6 \mathrm{~b}$ & $11.6 \mathrm{~b}$ & 0.1 & $P<0.01$ \\
\hline Yolk \% & 19.8 & 19.8 & 19.8 & 19.8 & 0.1 & NS \\
\hline Yolk mass (g day ${ }^{-1}$ per hen) & $10.5 a$ & $9.7 \mathrm{~b}$ & $10.6 \mathrm{a}$ & $10.8 \mathrm{a}$ & 0.2 & $P<0.001$ \\
\hline
\end{tabular}

Values in a row with different letters differ significantly at the level of the $F$ test; NS, not significant $(P>0.05)$.

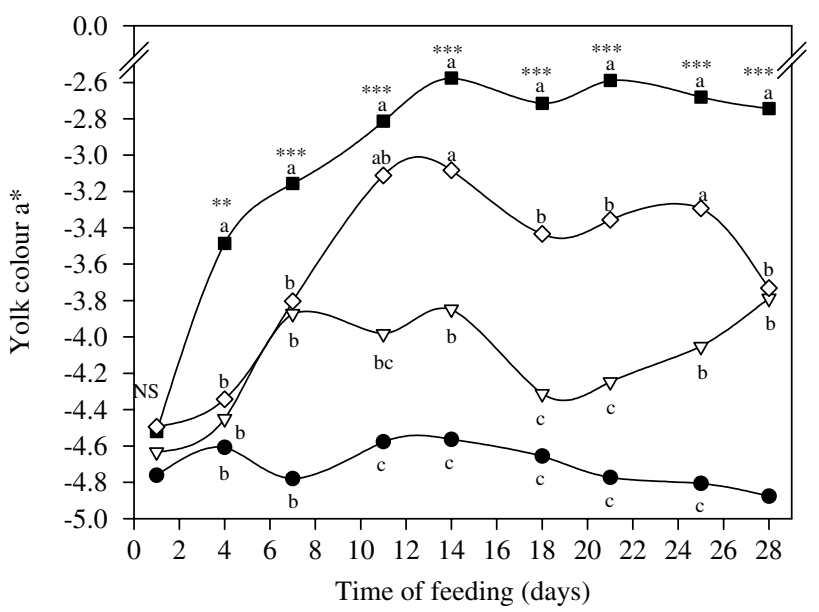

Figure 3. Egg yolk colour $a^{*}$ (redness) as a function of feeding time of dietary supplement of three carrot varieties Bolero $(\diamond)$, Rainbow $(\nabla)$ and Purple Haze (ם) compared with control treatment without carrot supplement $(\bullet)(n=10)$. For each time point, different letters indicate significant differences at ${ }^{* *} P<0.01$ or ${ }^{* * *} P<0.001$.

significantly $(P<0.001)$ with time, especially during the first $1-2$ weeks (Fig. 5). Again the highest response was in the purple carrot treatment, with lutein, $\beta$-carotene and total carotenoids reaching a constant level after about 2 weeks.

The carotenoid DE showed some variation dependent on the differences in nature of the carotenoids; hence lutein and zeaxanthin had average DE values of about $25 \%$, whereas $\beta$-carotene was deposited very inefficiently with a mean DE of $0.5 \%$ (Table 5). Lutein is the quantitatively most significant carotenoid in egg yolk, accounting for about 65\% (range 53-72\%) of the total carotenoid content. On average, yolks had relatively low $\beta$-carotene contents of about $1.2 \mathrm{mg} \mathrm{kg}^{-1}$, i.e. about $8 \%$ of the total. However, there was a 100 -fold variation in the content of $\beta$-carotene from yolks of the control treatment to yolks of hens supplemented with purple carrots rich in $\beta$-carotene (Table 5 ). A very high $\beta$-carotene content of $4.9 \mathrm{mg} \mathrm{kg}^{-1}$ yolk was found at day 28 of the purple carrot treatment (data not shown).

Correlations between the yolk colour variables $L^{*}, a^{*}$ and $b^{*}$ and the yolk concentration of different carotenoids showed that $\beta$-carotene concentration correlated logarithmically with yolk $a^{*}$ value $(r=0.618, P<0.001)$ (Fig. 6). Lutein concentration correlated to a lesser extent with yolk $a^{*}(r=0.225, P<0.05)$ and $b^{*}(r=0.233, P<0.05)$ values.

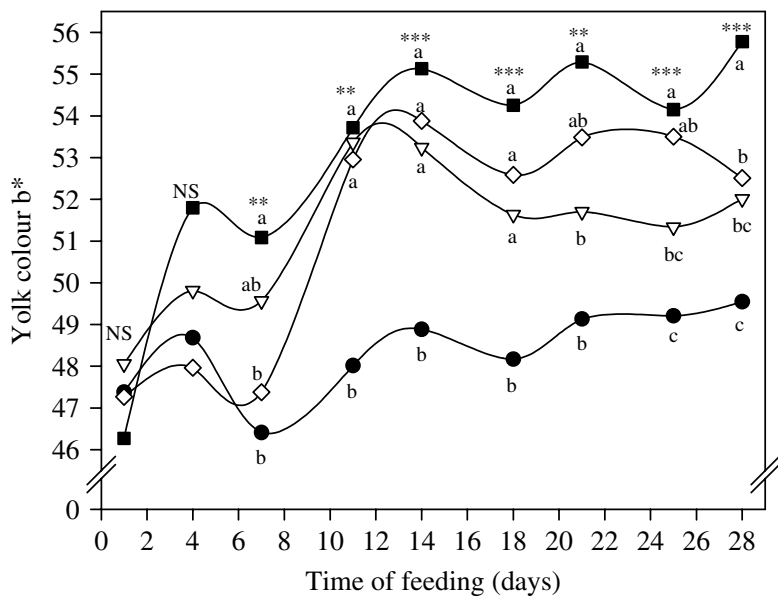

Figure 4. Egg yolk colour $b^{*}$ (yellowness) as a function of feeding time of dietary supplement of three carrot varieties Bolero $(\diamond)$, Rainbow $(\nabla)$ and Purple Haze $(\square)$ compared with control treatment without carrot supplement $(\bullet)(n=10)$. For each time point, different letters indicate significant differences at ${ }^{* *} P<0.01$ or ${ }^{* * *} P<0.001$.

\section{DISCUSSION}

The content of carotenoids in the presently used carrots is within the same range as reported by others, although there is large variation within each colour type. Orange carrots of different varieties have lutein concentrations ranging from $0.6-1.8^{14}$ to $2.6-4.4^{13} \mathrm{mg} \mathrm{kg}^{-1}$, of which the former compare to our data. In yellow carrot varieties, lutein concentrations may range from $1.3-2.3^{14}$ to $5.1^{13} \mathrm{mg} \mathrm{kg}^{-1}$, and in purple carrot varieties from $1.75-2.25^{14}$ to $11.0^{13} \mathrm{mg} \mathrm{kg}^{-1}$.

The present $\alpha$-carotene levels in orange, yellow and purple carrots were 1.5-10 times higher than previously reported values of $22.0,0.5$ and $4.1 \mathrm{mg} \mathrm{kg}^{-1}$ respectively. ${ }^{13}$ Nicolle et al. ${ }^{14}$ found $\alpha$-carotene levels of $12-31 \mathrm{mg} \mathrm{kg}^{-1}$ in orange carrots.

The $\beta$-carotene content was very high, about 85 and $120 \mathrm{mg} \mathrm{kg}^{-1}$ in the orange and purple varieties respectively, in accordance with previously reported concentrations of $32-$ $128 \mathrm{mg} \mathrm{kg}^{-1}$ in orange carrots and $3-123 \mathrm{mg} \mathrm{kg}^{-1}$ in purple carrots. $^{13-15}$ The yellow Rainbow variety had a lower level, although high compared with literature values of 1.8$3.3 \mathrm{mg} \mathrm{kg}^{-1} \cdot$. $^{13,14}$

The differences in carotenoid composition and content in carrots illustrate the impact of other factors besides colour and DM content on the carotenoid profile, such as season, climate and storage time 


\begin{tabular}{|c|c|c|c|c|c|c|}
\hline Treatment Carrot variety & Control - & Orange Bolero & Yellow Rainbow & Purple Purple Haze & SEM & $F$ test \\
\hline \multicolumn{7}{|c|}{ Yolk concentration $\left(\mathrm{mg} \mathrm{kg}^{-1}\right)$} \\
\hline Lutein & $7.46 c$ & $8.25 c$ & $10.40 \mathrm{~b}$ & $12.23 a$ & 0.21 & $P<0.001$ \\
\hline Zeaxanthin & $2.60 \mathrm{a}$ & $2.23 b$ & $2.62 a$ & $2.15 b$ & 0.06 & $P<0.001$ \\
\hline$\alpha$-Carotene & $0.01 d$ & $0.58 b$ & $0.16 c$ & $1.29 a$ & 0.02 & $P<0.001$ \\
\hline$\beta$-Carotene & $0.03 d$ & $1.84 b$ & $0.52 c$ & 3.39a & 0.06 & $P<0.001$ \\
\hline Total carotenoids & $10.83 c$ & $13.97 b$ & $14.76 b$ & $20.24 a$ & 0.31 & $P<0.001$ \\
\hline \multicolumn{7}{|l|}{ Deposition efficiency (\%) } \\
\hline Lutein & $24.8 \mathrm{a}$ & $19.5 b$ & $27.4 a$ & $18.8 \mathrm{~b}$ & 1.0 & $P<0.001$ \\
\hline Zeaxanthin & $25.6 a$ & $18.9 \mathrm{~b}$ & $27.9 a$ & $20.1 b$ & 1.0 & $P<0.001$ \\
\hline$\alpha$-Carotene & $0.9 a$ & $0.2 c$ & $0.5 b$ & $0.3 b c$ & 0.1 & $P<0.001$ \\
\hline$\beta$-Carotene & $1.0 \mathrm{a}$ & $0.3 c$ & $0.5 b$ & $0.5 b$ & 0.1 & $P<0.001$ \\
\hline Total carotenoids & $20.8 a$ & $1.4 \mathrm{c}$ & $7.0 \mathrm{~b}$ & $1.5 \mathrm{c}$ & 0.6 & $P<0.001$ \\
\hline
\end{tabular}

Values in a row with different letters differ significantly at the level of the $F$ test.

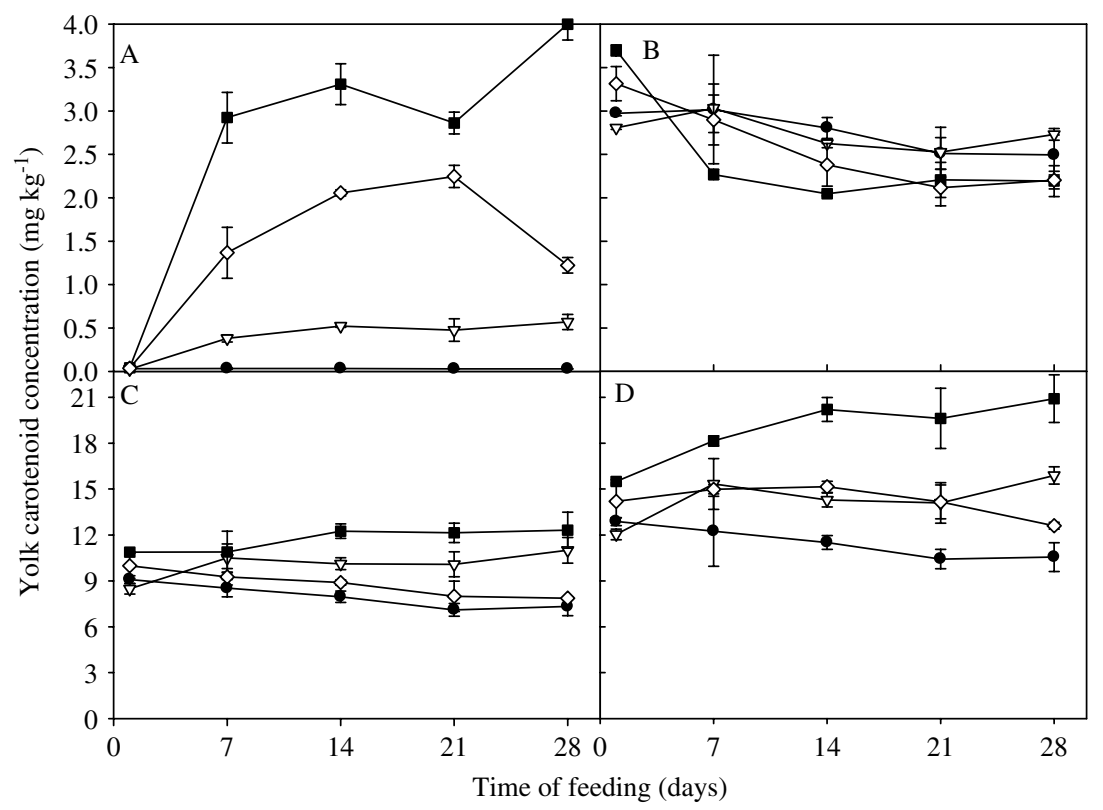

Figure 5. Time development of mean \pm SE of yolk carotenoid concentration as a function of dietary treatments, i.e. control $(\bullet)$ and supplement of carrot varieties Bolero $(\diamond)$, Rainbow $(\nabla)$ and Purple Haze $(\square)$ : A, $\beta$-carotene; B, zeaxanthin; C, lutein; D, total carotenoids $(n=6)$.

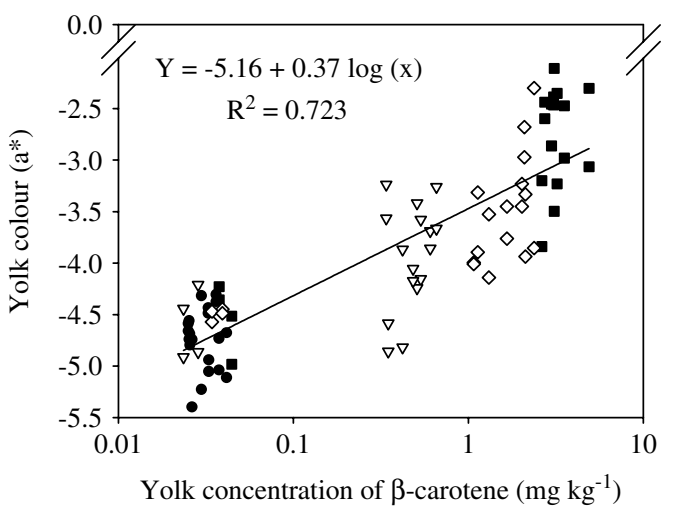

Figure 6. Correlation between yolk colour $a^{*}$ value and $\beta$-carotene content of egg yolk for eggs of four dietary treatments, i.e. control $(\bullet)$ and supplement of carrot varieties Bolero $(\diamond)$, Rainbow $(\nabla)$ and Purple Haze $(\mathbf{\square})$. and temperature of the carrots. ${ }^{15}$ These factors were not included in the present study but should be addressed in order to provide a basis for practical usage of carrot varieties as a forage material supplying laying hens and eggs with carotenoids.

The lower feed intake for hens supplied with forage material contrasts a previous study where feed intake was unaffected by inclusion of maize silage and carrots ( $123 \mathrm{~g} \mathrm{day}^{-1}$ per hen) compared with hens not given forage material. ${ }^{19}$ The observed decline in feed intake was hardly due to physical inability to consume the same amounts of feed together with the $70 \mathrm{~g}$ of carrots given daily, as hens previously have consumed daily $116 \mathrm{~g}$ of feed and $123 \mathrm{~g}$ of forage material ${ }^{19}$ or $130 \mathrm{~g}$ of feed and $110 \mathrm{~g}$ of forage material. ${ }^{23}$ However, hens at the age of 22-55 weeks eating $108 \mathrm{~g} \mathrm{day}^{-1}$ of orange carrots consumed $16 \mathrm{~g}_{\text {day }}{ }^{-1}$ per hen less feed compared with unsupplemented control groups. ${ }^{21}$ Furthermore, the present yellow and purple carrot-supplemented groups had numerically higher egg-laying rate and egg mass 
production, which could indicate supply of nutrients and energy from the carrots. Carrots are high in sugars and soluble non-starch polysaccharides (NSPs). It is assumed that carrots can supply the hens with energy from microbial fermentation of sugars and soluble NSPs, resulting in reduced intake of the standard feed.

The observed decrease in egg weight by carrot supplement is also seen for hens fed a diet with $8 \%(\mathrm{w} / \mathrm{w})$ dried carrot meal for 9 weeks, although insignificant. ${ }^{17}$ Interestingly, the carrot meal diet increased the laying rate from $60.7 \%$ (control diet) to $65.2 \%$, which corresponds to the present effect of yellow and purple carrots, whereas the orange carrot treatment had the opposite effect. Maize silage and carrots (orange) as forage material do not affect the laying rate, but egg weight decreases. ${ }^{19}$ In contrast to the observed effects on laying rate, the reduced egg weights may indicate a lower nutrient supply from carrot-supplemented hens. Decrease in feed intake may lead to inadequate supply of essential amino acids and, especially if the methionine intake is below requirement, the egg weight may drop. ${ }^{19}$ Based on feed and carrot intakes (Table 3), DM contents (Table 2) and methionine contents of feed (Table 1) and carrots, ${ }^{19}$ the methionine intake was calculated to be $318 \mathrm{mg} \mathrm{day}^{-1}$ per hen for the yellow carrot treatment, $348 \mathrm{mg}$ day $^{-1}$ per hen for the control and $328-329 \mathrm{mg}$ day $^{-1}$ per hen for the orange and purple carrot treatments. As the requirement is approximately $300 \mathrm{mg} \mathrm{day}^{-1}$ per hen, ${ }^{24}$ these methionine intakes are unlikely to result in decreased egg weight (Table 3). In summary, unknown factors in carrots seem to increase or decrease egg-laying rate dependent on carrot variety, and generally decrease egg weights. Further studies on a long-term basis are needed in order to elaborate on these effects.

The lutein intake was highest with purple carrot supplement, reaching a level of about $0.8 \mathrm{mg} \mathrm{day}^{-1}$ per hen (Fig. 2). Based on the composition of feed and carrots, the total carotenoid contents were calculated to be $5 \mathrm{mg} \mathrm{kg}^{-1}$ in the control and 14, 57 and $91 \mathrm{mg} \mathrm{kg}^{-1}$ in the yellow, orange and purple carrot treatments respectively. In an experiment with addition of $0-1000 \mathrm{mg} \mathrm{kg}^{-1}$ lutein to laying hen diets, the yolk colour was mainly affected from 0 to $250 \mathrm{mg} \mathrm{kg}^{-1}$ diet, whereas, beyond $375 \mathrm{mg} \mathrm{kg}^{-1}$, saturation was reached and the colour did not increase further. ${ }^{7}$ This limit or steady state for absorption and deposition of carotenoids in the yolk depends on the polarity of each carotenoid. The less polar molecule of $\beta$-carotene at a dietary level of $300 \mathrm{mg} \mathrm{kg}^{-1}$ has no yolk-colouring effect, whereas, for example, $50 \mathrm{mg} \mathrm{kg}^{-1} \beta$-8apo-carotenoic acid ethyl ester of higher polarity provides a blood concentration similar to that of $300 \mathrm{mg} \mathrm{kg}^{-1} \beta$-carotene and significantly affects the yolk colour. ${ }^{25}$ High dietary levels of only yellow or red xanthophylls may result in off-coloured or too red and mottled egg yolks. ${ }^{1}$ Instead, a blend of yellow and red pigments is the most efficient means to obtain dark-orange yolks. ${ }^{9}$ Carrots mainly contain the yellow carotenoids lutein, zeaxanthin and $\alpha$ - and $\beta$-carotene, but the purple carrot also contains anthocyanins that are purple/red pigments, which may contribute to the effect on yolk colour of this treatment, but were not detected by HPLC analysis.

A diet containing $20 \%(\mathrm{w} / \mathrm{w})$ microalgae supplied the egg yolk with canthaxanthin that mainly increased the $a^{*}$ value from -4.7 for the control, which had $L^{*}, a^{*}$ and $b^{*}$ values comparable to our control treatment, to 16.1 , but without affecting the $b^{*}$ value. ${ }^{26}$ In comparison, all present carrot supplements gave a relatively smaller but significant increase in both $a^{*}$ and $b^{*}$ values compared with the control (Table 4).

The DE varied with each carotenoid and its dietary concentration. In other studies the DE of lutein ranges from 2 to $38.9 \%$ and is shown to depend on its dietary concentration, ${ }^{7,20}$ i.e. lower dietary lutein content increases the DE.7 Supplementation of lutein from different dietary sources may result in concentrations of about 7-120 mg kg ${ }^{-1}$ yolk. ${ }^{7,10,12,20,27}$ The zeaxanthin content was relatively low, about $2.5 \mathrm{mg} \mathrm{kg}^{-1}$ egg yolk, compared with literature values of $0.2-13 \mathrm{mg} \mathrm{kg}^{-1}$ yolk. ${ }^{7,10,20,27}$

The low DE of $\beta$-carotene of about $1 \%$ is in accordance with results for quail eggs, with $\beta$-carotene $\mathrm{DE}$ values of $0.4-3.8 \%$, i.e. concentrations up to $0.5 \mathrm{mg} \mathrm{kg}^{-1}$ yolk. ${ }^{20}$ In contrast, we found a relatively high content of $\beta$-carotene of $1.7-3.3 \mathrm{mg} \mathrm{kg}^{-1}$ in yolks of the orange and purple carrot treatments. Feeding egg layers with carrot leaves results in a yolk $\beta$-carotene content of $0.8 \mathrm{mg} \mathrm{kg}^{-1}, 28$ and a dietary $\beta$-carotene level of $200 \mathrm{mg} \mathrm{kg}^{-1}$ results in $5.2 \mathrm{mg} \mathrm{kg}^{-1}$ yolk. ${ }^{29}$ As mentioned previously, $\beta$-carotene is not ascribed to be efficient in yolk pigmentation owing to both its poorer absorption than xanthophylls with higher polarity ${ }^{25}$ and also a high vitamin A activity of about $1167 \mathrm{IU} \mathrm{\textrm {mg } ^ { - 1 }}$ compared with $\alpha$-carotene ( $880 \mathrm{IU} \mathrm{mg}^{-1}$ ) and $\beta$-apo- $8^{\prime}$-carotenoic acid ethyl ester (420 IU mg $\left.{ }^{-1}\right){ }^{30}$ Generally, compounds of high vitamin A activity have low pigmenting ability. Nevertheless, the deposition of $\beta$-carotene in the yolk may affect the yolk colour at the relatively high levels observed. Hens fed only the standard feed remained at a low $\beta$-carotene concentration $\left(<0.05 \mathrm{mg} \mathrm{kg}^{-1}\right.$ yolk). The yolk content of $\beta$-carotene depends on the efficiency of the physiological mechanisms of each avian species by which carotenoids are transferred from intestine to ova, with egg yolks of e.g. coot and gull containing extremely high amounts of $\beta$-carotene $\left(19-33 \mathrm{mg} \mathrm{kg}^{-1}\right){ }^{31}$ The large difference in yolks between the domestic hen and the reported wild birds may reflect different antioxidant requirements by the chick embryos. ${ }^{31}$ We found interesting results on the yolk content of $\beta$-carotene, which has so far not been ascribed to be important for either yolk colouring or efficient deposition. It is speculated that, when the vitamin A requirement of the hen for nutritional purposes is fulfilled, the surplus of $\beta$-carotene is deposited in the yolk.

The average $\alpha$-carotene concentration of about $0.4 \mathrm{mg} \mathrm{kg}^{-1}$ in egg yolk (Table 5) was considerably lower than the level of about $3.0 \mathrm{mg} \mathrm{kg}^{-1}$ reported by Harder et al. ${ }^{32}$ The literature on $\alpha$-carotene content in yolk is sparse, so the actual finding is difficult to discuss.

There are no official guidelines for intake of lutein to e.g. prevent human ARMD, but it should be above $1 \mathrm{mg} \mathrm{day}^{-1}$, and intakes of 6-10 $\mathrm{mg} \mathrm{day}^{-1}$ are recommended. ${ }^{33}$ Using the present results for calculating the intakes to supply $1 \mathrm{mg}$ of lutein, either $84 \mathrm{~g}$ of yolk (seven eggs) from hens supplemented with purple carrots, $129 \mathrm{~g}$ of yolk (11 eggs) from hens of the control treatment, $154 \mathrm{~g}$ of the purple carrot variety Purple Haze or $592 \mathrm{~g}$ of the orange carrot variety Bolero is required. It is important to notice that the bioavailability of lutein is higher from eggs than from vegetables; for example, the lutein bioavailability from eggs is about three times higher than that from spinach. ${ }^{11}$

In conclusion, the use of coloured carrots as forage material for egg-laying hens increased the total carotenoid concentration in the egg yolk to a level $25-75 \%$ higher than that from hens not fed carrots. Of the individual carotenoids, lutein increased by up to $54 \%$ and $\beta$-carotene 100 -fold. The purple carrot variety had the highest concentration of both lutein and $\beta$-carotene and hence this variety had the significantly highest impact on egg yolk carotenoid content. The egg yolk colour variables reflected the carotenoid content; in particular, the redness $\left(a^{*}\right)$ and yellowness $\left(b^{*}\right)$ correlated with the carotenoid composition of the egg yolk. The feed intake decreased significantly for hens supplemented 
with carrots compared with unsupplemented hens, but not on a DM basis. However, the laying rate of hens on the purple and yellow carrot treatments increased, but the orange carrot treatment had a negative effect on egg-laying rate, egg mass and yolk mass production. The egg weight and yolk weight of all carrot-supplemented hens decreased compared with the control. In particular, supplementation of yellow and purple carrots as forage material improved the nutritional value of the egg yolk.

\section{ACKNOWLEDGEMENTS}

The authors thank technician Kirsten L Balthzersen for hen management, technician Ivan Nielsen for carotenoid analysis, and senior consultant Gitte K Bjørn for carrot supply. The Danish Research Center for Organic Food and Farming financially supported the study.

\section{REFERENCES}

1 Adams CA, Pigmenters \& poultry feeds. Feed Compounder 5:12-14 (1985).

2 Nicolle C, Cardinault N, Aprikian O, Busserolles J, Grolier P, Rock E, et al, Effect of carrot intake on cholesterol metabolism and on antioxidant status in cholesterol-fed rat. Eur J Nutr 42:254-261 (2003).

3 Johnson EJ, The role of carotenoids in human health. Nutr Clin Care 5:56-65 (2002).

4 Sparks N-HC, The hen's egg - is its role in human nutrition changing? World Poultry Sci J 62:308-315 (2006).

5 Bedecarrats GY and Leeson S, Dietary lutein influences immune response in laying hens. J Appl Poultry Res 15:183-189 (2006).

6 Granado F, Olmedilla B and Blanco I, Nutritional and clinical relevance of lutein in human health. Br J Nutr 90:487-504 (2003).

7 Leeson S and Caston L, Enrichment of eggs with lutein. Poultry Sci 83:1709-1712 (2004).

8 Leth T, Jakobsen J and Andersen NL, The intake of carotenoids in Denmark. Eur J Lipid Sci Techol 102:128-132 (2000).

9 Nys Y, Dietary carotenoids and egg yolk coloration - a review. Arch Geflügelk 64:45-54 (2000).

10 Handelman GJ, Nightingale ZD, Lichtenstein AH, Schaefer EJ and Blumberg JB, Lutein and zeaxanthin concentrations in plasma after dietary supplementation with egg yolk. Am J Clin Nutr 70:247-251 (1999).

11 Chung HY, Rasmussen HM and Johnson EJ, Lutein bioavailability is higher from lutein-enriched eggs than from supplements and spinach in men. J Nutr 134:1887-1893 (2004).

12 Surai PF, MacPherson A, Speake BK and Sparks N-HC, Designer egg evaluation in a controlled trial. Eur J Clin Nutr 54:298-305 (2000).

13 Surles RL, Weng N, Simon PW and Tanumihardjo SA, Carotenoid profiles and consumer sensory evaluation of specialty carrots (Daucus carota, L.) of various colors. JAgricFood Chem 52:3417-3421 (2004).

14 Nicolle C, Simon G, RockE, Amouroux P and Remesy C, Genetic variability influences carotenoid, vitamin, phenolic, and mineral content in white, yellow, purple, orange, and dark-orange carrot cultivars. J Am Soc Hort Sci 129:523-529 (2004).
15 Grassmann J, Schnitzler WH and Habegger R, Evaluation of different coloured carrot cultivars on antioxidative capacity based on their carotenoid and phenolic contents. Int J Food Sci Nutr 58:603-611 (2007).

16 Bjørn GK and Villebro J, Carrot varieties 2005. Internal Report, Danish Institute of Agricultural Sciences, pp. 1-20 (2006). (in Danish).

17 Sikder AC, Chowdhury SD, Rashid MH, Sarker AK and Das SC, Use of dried carrot meal (DCM) in laying hen diet for egg yolk pigmentation. Asian Aust J Anim Sci 11:239-244 (1998).

18 Zia R, Sakhawat A, Ahn AD and Shah FH, Utilisation of fruit and vegetable wastes in layers' diet. J Sci Food Agric 65:381 - 383 (1994).

19 Hammershoj $M$ and Steenfeldt S, Effect of blue lupin (Lupinus angustifolius) in organic layer diets and supplementation with foraging material on layer performance and some egg quality parameters. Poultry Sci 84:723-733 (2005).

20 Karadas F, Grammenidis E, Surai PF, Acamovic T and Sparks C, Effects of carotenoids from lucerne, marigold and tomato on egg yolk pigmentation and carotenoid composition. $\mathrm{Br}$ Poultry Sci 47:561 - 566 (2006).

21 Steenfeldt S, Kjaer JB and Engberg RM, Effect of feeding silages or carrots as supplements to laying hens on production performance, nutrient digestibility, gut structure, gut microflora and feather pecking behaviour. Br Poultry Sci 48:454-468 (2007).

22 Britton G, Structure and properties of carotenoids in relation to function. Faseb J 9:1551-1558 (1995).

23 Horsted K, Hammershoj M and Hermansen JE, Short-term effects on productivity and egg quality in nutrient-restricted versus nonrestricted organic layers with access to different forage crops. Acta Agric Scand A 56:42-54 (2006)

24 National Research Council, Nutrient Requirements of Domestic Animals. National Academy Press, Washington, DC, pp. 1-155 (1994).

25 Na JC, Song JY, Lee BD, Lee SJ, Lee CY and An GH, Effect of polarity on absorption and accumulation of carotenoids by laying hens. Anim Feed Sci Technol 117:305-315 (2004).

26 Fredriksson S, Elwinger $\mathrm{K}$ and Pickova J, Fatty acid and carotenoid composition of egg yolk as an effect of microalgae addition to feed formula for laying hens. Food Chem 99:530-537 (2006).

27 Schlatterer Jand Breithaupt DE, Xanthophylls in commercial egg yolks: quantification and identification by HPLC and LC-(APCI)MS using a C30 phase. J Agric Food Chem 54:2267-2273 (2006).

28 Ishikawa S, Murakami H, Yamazaki M and Takemasa M, Effect of carrot leaf supplementation on egg yolk beta-carotene content and egg quality. Jpn Poultry Sci 36:275-283 (1999).

29 Jiang YH, Mcgeachin RB and Bailey CA, Alpha-tocopherol, betacarotene, and retinol enrichment of chicken eggs. Poultry Sci 73:1137-1143 (1994).

30 Hencken $\mathrm{H}$, Chemical and physiological behavior of feed carotenoids and their effects on pigmentation. Poultry Sci 71:711-717 (1992).

31 Surai PF, Speake BK, Wood NAR, Blount JD, Bortolotti GR and Sparks NHC, Carotenoid discrimination by the avian embryo: a lesson from wild birds. Comp Biochem Physiol B 128:743-750 (2001).

32 Harder MNC, Canniatti-Brazaca SG, Coelho AAD, Savino VJM and Franco CFO, Cholesterol and iron availability in yolk of laying hens feed with annatto (Bixa orellana). Animal 1:477-482 (2007).

33 Seddon JM, Ajani UA, Sperduto RD, Hiller R, Blair N, Burton TC, et al, Dietary carotenoids, vitamin- $A$, vitamin- $C$, and vitamin- $E$, and advanced age-related macular degeneration. J Am Med Assoc 272:1413-1420 (1994). 